\title{
Blockchain and Cryptocurrencies - Considerations for Treatment and Reporting for Financial Services Professionals
}

Sean Stein Smith. Lehman College, City University of New York, Sean.Steinsmith@lehman.cuny.edu

Rossen Petkov. Lehman College, City University of New York

Richard Lahijani. Lehman College, City University of New York

\begin{abstract}
The rise and continued implementation of cryptocurrencies and other cryptoassets is having, and will continue to have, a disruptive impact on the accounting, federal income taxation, and broader financial services industries. Much has been written, researched, and discussed about both cryptocurrencies and the underlying blockchain technology, but uncertainty remains as it pertains to how these items should be reported for accounting and tax purposes. What this research attempts to accomplish, through both a review of the literature and publicly available guidance issued by tax and accounting authorities, is to document and analyze what current guidance represents for financial reporting. Additionally, this research proposes how future iterations of cryptoassets and cryptocurrencies might be reported, with recommendations applicable for both practitioners and academics seeking to expand on this work.
\end{abstract}

Keywords: cryptocurrencies, accounting, cryptoassets, blockchain, innovation, change management 


\section{INTRODUCTION}

The global business landscape, regardless of industry, geographic boundary or location, is in the midst of a paradigm shift when it comes to how business is conducted, organizations are valued, and where the accounting profession sits in this dialogue. Specifically, the rise and implementation of different types of cryptoassets, including cryptocurrencies, are disrupting how business is conducted between individuals and organizations. In addition to the changes to business processing and the transmission of information between different entities, the accounting profession is also being disrupted by these changes. Examined throughout this piece, it is important to recognize and acknowledge that several of the core competencies previously occupied and serviced by accounting and attestation professionals will experience displacement due to these technological changes. Prior to drilling down to the specific implications and developments for the profession, however, it is logical to first conduct a review of what exactly these different assets represent, how they are utilized, and future applications of these items are projected to be.

Additionally, and taking into account the reality that definitive guidance remains unavailable as of this writing, this research attempts to address two of the critical issues facing the profession and practitioners employed within. First, defining and understanding the working definition of blockchain and cryptocurrencies is imperative for practitioners seeking to offer advisory services or utilize said tools. Second, and forming the portion of this research applicable to both practitioners and academics, considerations and options are presented to address options as to how these various cryptoassets and cryptocurrencies fit into the accounting and reporting paradigm. Particularly with the amount of investment, interest, and research underway in the area, such considerations do not represent merely theoretical concerns.

An important distinction to draw initially, however, is to differentiate cryptoassets from cryptocurrencies. Cryptocurrencies, most commonly associated with Bitcoin, are digitally created and stored mediums of exchange that are decentralized, not associated with a nation state (like fiat currency options are), and can, to varying degrees, provide anonymity for users of these tools (Sontakke and Ghaisas, 2017). While it is true that Bitcoin continues to, both in practitioner discussion and academic research, dominate the conversation, there are many options, including 
Bitcoin, but including hundreds of others, are labeled and discussed as currency options, they are not treated as such by taxation and reporting situations. Instead, these cryptocurrencies are treated as any other asset, which can be thought of any digital information that is protected by some combination and utilization of encryption tools. Regardless of specific labels used in conversation, in other words, cryptocurrencies are taxed as if they were equity securities. What remains, to date, an area of uncertainty is how these different currency options will be reported under GAAP and IFRS standards.

Both sets of information, cryptocurrency options as well as the more encompassing category of cryptoassets, are driving changes in business across industry lines. A primary benefit, and disruptive force behind the adoption of these different tools is the reduction of informational friction that is possible to achieve through implementation. Put simply, if information, which can include but is not limited to financial information, can be transmitted without the need of intermediaries, the scope of potential disruption is enormous. Accounting and financial services professionals, whose scope of competencies include data verification, analysis, and reporting, traditionally have performed the role and duties associated with intermediary services. Drilling into current research and literature, however, paints a picture of a future in which these duties must evolve and change alongside the rise of cryptoassets.

\section{LITERATURE REVIEW}

\section{Blockchain}

Prior to understanding cryptocurrencies, cryptoassets, or the connections between cryptoassets and accounting it appears logical to conduct a review of the technology that underpins this entire asset environment. Blockchain technology forms the foundation of how virtually every cryptoasset and cryptocurrency interacts not only with other assets in this classification category, but the broader business environment. This platform functions as an appropriate base from which cryptoassets can be utilized and developed for a number of reasons, including similarities in terms of technical functionality. In an alignment that does not appear to be a coincidence, this alignment of functionality is also associated with core functionality of blockchain technology itself. Analyzing these different components of the blockchain technology and platform is essential for 
practitioners and academics seeking to understand either cryptoassets, or the accounting implications of these assets.

A common misconception in the marketplace is that blockchain technology is a finance, financial reporting, or otherwise accounting oriented tool or platform, but this only represents a partial view of the functionality embedded in this technology. Rather, blockchain can be more accurately thought of as a database structure, akin to Excel or Access, with several additional attributes that differentiates it from existing technology options (Adams and Sumutka, 2018).

Drilling down into the specific functionality of blockchain highlights the differentiating factors the make blockchain such a relevant and market oriented topic also of interest to academic research.

Immutability is a key factor of blockchain technology in that this platform enables, via time stamp verification and some sort of consensus verification, the locking in of information, uploaded via blocks, into the existing blockchain data structure (Carlozo, 2017a) Additionally, once this information has been verified and uploaded onto the blockchain, it cannot be altered unless the initial data is reversed, and re-uploaded in a fresh block of information. One consideration that must be taken into account, even as audit and attestation is altered by such immutability, is the fact that this very immutability may run afoul of regulation (Herian, 2018). Another, and arguably the most important factor that sets blockchain aside from other networking and database tools, is the fact that it is a decentralized data platform. Put simply, this decentralized nature means that there is no central regulatory or approving body or bodies overseeing the blockchain network (Carlozo, 2017b). While this does it more difficult to obtain resolution in the case of hacks, data breaches, or unsatisfactory transactions, it also assists in increasing the potential business applications of this platform

Cryptocurrencies and cryptoassets in general were created, and are utilized, to help facilitate the flow of information between individuals and/or institutions with less friction and fewer intermediaries than exist in the current business environment (Luther, 2016). The consensus methodology of blockchain, whether it takes the form of proof of work, proof of stake, or a consortium agreement of approving parties, enables these blockchains to exist outside of traditional regulatory or governmental frameworks. Since these cryptocurrency assets do not exist or trade within the usual guidelines of fiat currency, or currency that is 
created and managed by a government or quasi-governmental institution, the accounting for these assets can be more complicated than would be initially apparent. Expanded upon below and throughout this piece, the accounting treatment of these items can seem contradictory, especially for practitioners seeking to explain these concepts to clients in a public practice setting.

\section{Public versus private blockchain}

Following a review of the literature, and scope of implementation of blockchain in the current business environment, it is important to recognize the reality that the label of blockchain does not mean the functionality is equivalent across all options. While there are a variety of options available for adoption by industry specific group, beyond the scope of this research, there is one distinction that must be drawn in the context of blockchain adoption and implementation. A public blockchain, such as the one utilized by Bitcoin, which is also the largest and most well established network in existence, allows any potential participant to join the network and begin participating in blockchain transactions and verifying transactions as they are added to the network. Public blockchains allow any individual or institution to join this network, which adheres to the decentralized nature of the idea, but can also result in lags in transaction speed, hindering it for processing business transactions. This lag in transaction processing, which may not appear tremendous at first glance, must be compared to the speed with which current financial transactions can be completed and verified nearly instantaneously.

Private blockchains, conversely, operate in a slightly different manner from public blockchains in that not everyone is able to automatically join the network. Opposed to downloading the network program, installing it on a server, and automatically being granted access to the blockchain network, private blockchains almost always involve some sort of invitation to join. Specifically the ability of private blockchain, or a consortium blockchain managed by a smaller subset of users, has potential to play a definitive role as an AML tool or asset within the network or organization (Lai, 2018). This selectivity of who, again from an individual or institutional perspective, can join a private blockchain, does limit the decentralized attribute so often associated with blockchain technology. That said, it is also important to recognize that, by controlling who can join and participate in the blockchain network, several benefits are can be identified in relatively short 
order, specifically increasing the speed with which transactions and information can be verified and finalized.

It is important to note and acknowledge the reality that, regardless of the blockchain platform utilized by different organizations or groups of organizations, that cryptoassets and cryptocurrencies are governed by the regulations underpinning the blockchain itself. Accounting treatment and reporting, although the focus of this research and analysis, is merely one aspect and part of the consideration and analysis required of different cryptoassets and cryptocurrencies. Taking this one step further, it appears logical to differentiate and distinguish between two terms - cryptoassets and cryptocurrencies - that are often used as if they were interchangeable in nature.

\section{Cryptoassets versus cryptocurrencies}

In the avalanche of media coverage and analysis that continues to dominate the conversation and debate around cryptoassets and cryptocurrencies it is important to differentiate these two distinct categories of assets prior to drilling into accounting specific implications.

Cryptocurrencies, most notably illustrated and highlighted by Bitcoin, are decentralized currency tools that are not governed by any central government, do not qualify as a traditional fiat currency, and provide some level of anonymity for users (Luther, 2015). Such a categorization, by the media, consumers, and business organizations can add to the confusion related to the accounting treatment of these items. Applications and options for how to account for these items are outlined below, but it is important to recognize that cryptoassets do not necessarily correlate to cryptocurrencies. It may be argued that drilling down to this level of granularity is unnecessary at this point, a nascent stage, in the reporting and taxation conversation, but omitting this will only provide a partial and incomplete view of the landscape.

Rather, making clear the distinction between cryptocurrencies and cryptoassets lays the groundwork for a comprehensive discussion and analysis of just how the different accounting options may be implemented moving forward. Beginning with the concept of cryptocurrencies, which continue to receive the majority of coverage and analysis allocated to blockchain based applications, appears a logical step. Cryptocurrencies may indeed, one day in the future, achieve status as 
an alternative or even primary medium of exchange for consumer purchases, but as of this research, there are several issues preventing this possibility from beginning reality. First, the volatility of these different currency tools makes it difficult to ascertain an appropriate value to report for income statement and balance sheet reporting purposes. It is true that other currencies, including major fiat currencies that dominate the global currency landscape, do experience volatility on an ongoing basis, the magnitude of cryptocurrency volatility and regulatory uncertainty makes it difficult to calculate a reliable value for reporting purposes, particularly from a tax reporting and compliance perspective (Jackson, 2018). Second, although these various options, and it is important to remember that the total available options number in the thousands, are labeled as currency, they are not truly used as a currency option. This schism between perception and reality raises several other questions regarding the most appropriate methodology for reporting and disclosure of this information. Third, and perhaps most important for the profession moving forward, is the cryptography and other sorts of encryption that forms the underpinning of how these different items are secured and labeled. A question remaining unaddressed in the current guidance and literature is if the cryptocurrencies do indeed grant users, both buyers and sellers included, anonymity, how are accounting professionals supposed to audit or attest to this information with any substantial accuracy?

Cryptoassets, on the other hand, represent the totality of assets and information available to be stored and processed, via a blockchain platform and possible secured using a system of cryptographic protection and encryption. Whereas a cryptocurrency, at its essence, strives to present at least some sort of anonymity for users of the item, cryptoassets do not necessarily have to abide by that structure. Rather, the concept of a cryptoasset or a crypto-enabled asset can include a much broader range of activity and information, many of which are actually familiar to business users, or simply augment existing offerings in the marketplace. For example, a smart contract, which is a contract whose terms and conditions, subsequent to approval and verification by interested parties, is uploaded and executed via a blockchain platform, is an example of something that may in fact qualify as a cryptoasset if cryptography is utilized to help secure this information. Understanding this concept, the landscape of what may possible qualify for treatment and classification as a cryptoasset begins to expand at a relatively rapid pace, including a shift toward blockchain based accounting 
systems (Dai and Vasarhelyi, 2017). In essence, any information, contract, agreement, or business related item that is both embedded in a blockchain environment and secured using some sort of cryptographic information. Insurance payout arrangements, joint venture specifications, patent filings, and virtually any other intangible or intellectual asset may qualify, if structured appropriately, as a crypto-enabled asset. The fact that the guidance, both within the United States and on an international level, is incomplete as of this writing only adds to the possible confusion.

\section{IMPACT OF CRYPTOASSETS ON ACCOUNTING}

\section{Financial Statements' Implications}

In the following paragraphs, we discuss the potential accounting treatment for crypto assets. In the recent literature, there have been some unambiguity as to how these types of items should be treated and therefore recorded in the financial statements of the company. As we have previously noted in the paper, crypto currencies or bitcoins are considered to be a sub category of crypto assets. Therefore, it appears to be appropriate to evaluate the potential accounting treatment of such currencies could be applied to cryptoassets as whole. We start the discussion as such and later follow with alternative treatments of cryptoassets as either investments or intangible assets.

Some have argued that the bitcoins (refer to the distinction between cryptoassets and crypto coins from above) could be treated as part of Cash and Cash Equivalents (Bjerg, 2016; De Filippi, 2014; Ly, 2013; Pagliery, 2014; Yermack, 2015). The advocates for this treatment have argued that crypto coins can be used in certain legal tenders (De Filippi, 2014; Ly, 2013). However, there is some questionability on these accounting treatments as many countries have started banning these types of legal payments (Smart, 2015). The main argument against these payments is that it has been shown in the past to be used to fund illegal activities and terrorism (Reynolds and Irwin, 2017). Therefore, there is some illegality associated with their use. We note that even though crypto currencies could be banned or not included as part of the payment system of a specific country, people could still use them to barter goods. We can advocate that bitcoins (as an example) could be viewed as they way gold or silver are used to pay for goods. That is, even though gold and silver are not used as legal tender in some 
countries, they are still used in certain private market transactions. However, from a legal point view, the disallowance of cryptocurrencies as legal tenders in many countries denies the accounting treatment of these items as Cash Equivalents. Based on this analysis, it does not appear appropriate to account for crypto assets as cash and cash equivalents as there is not currently available market to determine the cost over time.

An alternative treatment for cryptocurrencies and subsequently cryptoassets are to record them as investments on the balance sheet. The argument for this treatment is that bitcoins and/or other types of cryptoassets represent a type of an investment vehicle and therefore, should be treated as such. The main argument for such treatment is that cryptocurrency and assets could be purchased externally and therefore we could assign appropriate value at the time of purchase. In addition, at a later point, we can make adjustment to reflect the market conditions similar to the accounting treatment for investments. In accounting, investments (less than $20 \%$ ) are recorded at cost and subject to continuous revaluation to market at the end of the reporting period. We could use this similar treatment for crypto currencies and measure and adjust their value appropriately over time. However, there are some constraints to this treatment. As we have previously noted, there are many countries that have all together banned the use of these types of payments within their economic/market framework. As such, some can argue that the market prices (for the purposes of the revaluation to market) do not reflect the true market price as many of the market participants have been restricted access. Therefore, the market prices at any given point, do not really reflect the true aggregate supply and demand. From the perspective of cryptoassets, there is a greater inability to measure its cost over time. For such assets that we purchase externally, it would be almost impossible to measure their value over time as there is no existing market. For self createdcryptoassets, it would be impossible to measure their cost at the point of acquisition and subsequently their value over time. As such, this treatment appears to be inapproapriate to say the least for cryptoassets.

In this paper, we take a holistic view on the accounting treatment on cryptoassets. That is, we analyze in this section whether it would be appropriate to account for these assets as intangibles and therefore used some of the already established rules for recording the initial costs and a later period, assert this cost over time. We 
would start with the basics, noting that these items clearly meet the definition of an asset. From an accounting perspective, an asset is an item that is the result of past economic event, provides future benefits and can be controlled (FASB Statement 6, 1985). Clearly, crypto assets meet this definition as they are the result of the past, can be controlled and would provide future benefits for the company. These assets can originate either externally or internally. They provide future benefits for the company in terms of potential incremental in revenues. In addition, they can be controlled. That is, the owner could either sell or dispose of these items as he or she pleases. However, it is important to note these types of assets do not have any physical form or nor physical attribute of value. That is, these assets do not have physical attributes, they cannot be touched, held and physically transacted with. Therefore, it appears that they meet some of the attributes of intangibles and therefore further analysis is warranted in regards to the accounting treatment in the financial statements.

From an accounting perspective, there are two categories of intangibles - internal (or self-created by the company) and external (purchased from the outside) (Kaufmann and Schneider, 2004). Depending on the initial purchase/creation of the asset, there is a difference in the accounting treatment. Per US GAAP, externally purchased (created) assets are initially recorded at fair value (the price to purchase them) and subsequently recorded on the books at cost (FASB Statement 142, 2001). As the item is used, these externally generated intangibles are periodically accounted for either through the process of amortization (allocating the assigned cost over a period of time) or subject to impairment testing (when their life is deemed to be infinite). For internally generated assets, the accounting treatment is different. We expense all the cost of research and development of these types of assets (with certain exceptions).

Applying these same rules to cryptoassets, in the following subsection, we would analyze whether these assets could be treated in the same way as intangibles. That is, we would follow the established guidelines for accounting for external and internal intangible assets, and determine whether we can them in the same manner as intangibles. As a starting point, we would propose the following treatment and evaluate its applicability in regards to cryptoassets: 
- Externally created crypto-assets - record at cost and amortize based on their useful life (if such can reasonably be determined. Alternatively, test for impairment on periodic basis

- Internally created crypto-assets - expense all cost associate with the creation of such assets as they are incurred

For externally purchased crypto assets, it would be meaningful to record these at their purchase cost. Once recorded, we have to determine their useful life in order to amortize their cost over time. However, there is a complication as it would nearly impossible to estimate their useful life. As these assets do not have clear regulatory established useful life, it would be up to judgement of the company to determine the useful life. As there is no prior or recent experience of companies to account and/or measure such life, many management teams would have to set certain assumptions - not tested in time. This creates a high risk that the financial statements could be misstated. In addition, as we would discuss in the following section, these uncertainties create a higher audit risk for the external auditors.

Alternatively, if the company determines that the useful life cannot be reasonably determined, it needs to set certain policies and procedures to tests its value over time. That is, the company needs to set procedures to test the cost for impairment. There are arising issues with this type of a treatment as in order to test for impairment, the company would need to company up with its own estimation of the fair value of the crypto assets. This estimation would be based on assumptions. These assumptions would be difficult to be verified as there is no clearly established market (as the item could be very unique). Again, the previously stated concerns with financial reporting and audit risk would be present.

For internally created crypto assets, the accounting treatment clearly states that we would need to expense as incurred. This would create more opportunities for management to manipulate earnings. In addition, these are assets that could be used for more than one year and therefore, the expensing them would not reflect the true economic conditions of the company. That is, both types of crypto assets (external and internal) meet the definition of an asset, but only one would be recorded on the Balance Sheet. 
Based on this analysis, it becomes clear that there is not an appropriate all fit all accounting treatment for crypto assets and currencies. The key obstacle we face is establishing their appropriate fair value over time and their useful life. These two components are necessary to properly account for these assets. Therefore, prior to creating any set of rules or guidance, we need to create better tools or indicators to come up with these two variables.

\section{AUDIT IMPLICATIONS OF CRYPTOASSETS}

There are significant audit implications for companies who have either purchased or self- created cryptoassets in the course of their business. In this part of the discussion, we would analyze the audit impact on treating such assets on the balance sheet. As such, there are significant implications on both the internal and external auditors of the company. As part of this discussion, we would specifically focus on the impact of the inclusion of these assets on the balance sheet for external auditors. However, some of the conclusions reached here could also have a basis for the internal auditors.

The primary implications to external auditors are associated with measuring the value of these assets over time. We believe that auditors need to exercise extra care in determining whether the valuation of cryptoassets, recorded on the balance sheet, are accurate based on the proper underlying assumptions. In addition, there are significant audit implications on the verifiability and therefore the completeness of these types of assets. Overall, we believe that for cryptoassets, valuation could be a significantly high risk, as there are many assumptions and estimations involved. Existence and completeness can be also very highly risky assertions as the underlying information to determine whether the specific assets exist, is highly subjective and therefore subject to significant bias by the management.

As part of the statutory audit, external auditors need to provide reasonable assurance that the financial statements are free of material misstatements. In regard to auditing the cryptoassets, auditors need to properly understand the inherent and control risk associated with these types of accounts so that they can properly plan their audit procedures. As previously noted, there are significant implications associated with the completeness and valuation assertions in regard to cryptoassets. That is, companies as well as their external auditors would have significant difficulties asserting the proper value of these assets over time. As a 
result of this (based on our understanding that there is a high level of judgement and complexity of these assets), we believe that the inherent risk would be significant. For the purposes of controlling the risk of misstatements, most likely companies would try to establish adequate internal controls to prevent instances of material misstatements. For cryptoassets, mostly like these controls would involve a high level of multistage reviews of the assumptions used in the estimation of the values of these assets. In addition, there would be secondary controls to ensure the accuracy of the valuations of these assets. However, it is very unlikely that these controls would be effective as there is a lot of judgments used in the valuation stage. Based on this and our underlying theoretical review of the accounting treatment for cryptoassets, we believe that the control risk would be relatively high to medium. As far as the detection risk, we believe that in order to ensure detection risk is relatively low, the auditors need to need to plan more, and also, perform very effective audit procedures to ensure that overall risk of material misstatement is reduced to an acceptable level. To accomplish this and to reduce this risk to an acceptable level, auditors might need to involve high cost third party valuation specialists over time. However, such involvements would significantly increase the cost of the audit over time. Therefore, there are significant cost implications for external auditors to consider when either engaging a new client or continuing the audit services for existing clients.

\section{TAX IMPLICATIONS OF CRYPTOCURRENCY}

It is interesting to observe how the Internal Revenue Service (IRS) will tax and track compliance with respect to cryptocurrency. The IRS issued notice 2014-21 on March 25, 2014 in which it discussed sixteen frequently asked questions, giving some guidance on how taxpayers should treat the sale or exchange of a cryptocurrency. In its view, cryptocurrency (i.e. Bitcoins, Litecoin and others) is "property," thus general tax principles that apply to property transactions apply to transactions using virtual currency (IRS, 2014).

Internal Revenue Regulation Section 1.1001-1 states that "the gain or loss realized from the conversion of property into cash, or from the exchange of property for other property differing materially either in kind or in extent, is treated as income or as loss sustained. The amount realized from a sale or other disposition of property is the sum of any money received plus the fair market value of any property (other than money) received” (U.S. Treasury, 2018). Additionally, if a 
taxpayer has held the currency for more than a year, it is to be treated as a long term capital gain and will consequently be taxed at twenty percent for Federal income tax purposes. Furthermore, any property held for exactly one year or less is considered ordinary income and will be taxed at the highest individual rate (currently 37\%). Finally, each time a taxpayer divests of a cryptocurrency, it is considered a sale or exchange. Consequently if a taxpayer trades, sells, or buys a thousand different items it will have a thousand taxable events, as each is considered an individualtransaction. It is the author's view that cryptocurrency should be considered as "property” as defined under Internal Revenue Code (IRC) Section 317(a) (I.R.C., 1986a) and other applicable sections. The basis for this view is that given the fact that cryptocurrency is not backed by any sovereign government nor is it acceptable universally, it should be treated as any other stock, or business property is treated (i.e. generally capital asset).

Prior to the passage of the Tax Cuts and Jobs Act (TCJA) by President Trump on December 22, 2017, the taxpayer was allowed to treat the sale or exchange of cryptocurrency as an asset that would qualify for tax deferral under IRC Section 1031(a). This deferral allowed the taxpayer to defer the tax gain or loss until a later point in time. In theory, according to the prior regulation, the taxpayer could have deferred this gain until the end of time (I.R.C., 1986b). As a result, if a taxpayer traded or swapped one form of cryptocurrency for another it would have qualified as a 1031 asset. The TCJA revised IRC 1031, now allowing taxpayers to defer gain or loss on business assets that are considered real property (i.e. Real Estate).

In June of 2016, the American Institute of Certified Public Accountants (AICPA) wrote a letter to the IRS, imploring them to issue more guidance on the tax treatment of cryptocurrencies. In the letter, the AICPA mentioned the effort to "release additional, much needed, guidance on virtual currency." (AICPA, 2016).

However, to date there has not been any further guidance issued.

According to an affidavit from IRS agent David Utzke in 2015, only 802 individual taxpayers declared and paid federal income tax on gains related to bitcoin (IRS, 2015). There has been however, a monstrous amount of individuals who have invested in the cryptocurrency. And even though a taxpayer may not receive IRS form 1099 from the exchange where they trade the cryptocurrency, the onus is still on the taxpayer to report and pay any income taxes owed. In 2017, 
a U.S. district court in California ordered "Coinbase," one of the more famous platforms for buying and selling bitcoins and other cryptocurrencies, to send to the court identifying information on all of their account holders over a certain threshold amount. (U.S. vs. Coinbase, 2017). As of yet, it is too early to see the number of taxpayers who will declare and pay income tax on their 2017 cryptocurrency gains. However, given the pursuit of the IRS on these individuals, there will likely be an increase in enforcement of these laws. The IRS does have very broad authority under IRC Section 7602 to issue summonses to taxpayers and other third parties to ask for information to determine the correctness of any return (I.R.C. 1986c). It will be very interesting to see the extent to which the IRS would exercise their authority given the tremendous amount of budget cuts that they have suffered in recent years and the lack of "man power."

\section{ADDITIONAL ACCOUNTING IMPLICATIONS}

In addition to the audit, tax, and financial reporting implications and changes that are arising, and will continue to rise from the increased adoption of cryptocurrencies and other types of cryptoassets, other issues must be addressed and incorporated into regulations, discussions, and conversations around these items and assets moving forward. Prior to analyzing these additional issues, however, is it imperative to acknowledge the following reality. As of this writing there is a substantial amount of debate and conversation around how the guidelines and regulations of these items will be treated moving forward. Similar to any new technology tool or business application, this will invariably constitute an iterative process entailing a continuous feedback loop of information gathered from academic, practitioner, and industry specific participants and members. Against this framework, and realizing that current regulations and guidelines will evolve over time as the scope and pace of implementation change, several other factors become evident as worthy of consideration and analysis.

First, and generated directly by the cryptographic nature of the cryptocurrency and cryptoasset environment itself, there is a degree of anonymity embedded in public blockchain networks. Such anonymity does align with the central tenet of blockchain, which represents a decentralized system and methodology, but does results in longer processing and confirmation times for individual transactions that can limit the functionality of said a system for business purposes. Private blockchain networks, to the contrary, combine the peer to peer nature of 
blockchain technology while reducing friction, time, and costs associated with processing and confirming transactions. Second, and linking back to the issues raised related to accounting and tax reporting previously in this research, is the reality that the totality of this field is still, for all intents and purposes, in the beginning stages of adoption. This current uncertainty will undoubtedly create challenges for accounting professionals seeking to provide guidance and advice to clients or external colleagues. This same uncertainty, however, also provides a unique opportunity for accounting professionals to assume a position of leadership on these issues, and within organizations. While not usually an aspect associated with accounting professionals, or the profession at large, seizing on the momentum and interest in this area to become educated and informed on an area of emerging importance. Returning to the present, however, there are several future directions and implications that upon review of current literature and market guidance, become readily apparent when considering the appropriate treatment.

Additional considerations and factors that appear logical to consider and integrate into the decision making process are as follows, particularly as clients begin to invest increasing amounts of financial and human capital into the sector. Included in this analysis should also be the following; how exactly is the organization of individuals employed therein are using these various cryptoassets. While it remains unclear as to whether or not consideration will be given based on the utilization of said assets, this point should be mentioned and discussed as a possibility when considering classification parameters. Particularly as it would seem rationale to try and apply existing reporting frameworks to this emerging asset class, taking into account current differentiation might also be a logical aspect of the dialogue.

\section{DISCUSSION AND CONCLUSIONS}

The field and areas associated with cryptocurrencies and cryptoassets continue to dominate media coverage, practitioner publications, and academic research, but as of this writing there is limited guidance and advice for how organizations will treat these various assets moving forward. It is true that the IRS has offered substantive guidance on the treatment of cryptocurrencies, namely treating them as equivalent to equity securities, but that only addresses one aspect of accounting. The majority of financial reporting and analysis does not focus on tax 
analysis and information, but rather is centered around the reporting of GAAP or IFRS financial statements. Framed within existing guidelines there do appear to be several options for how organizations could account for, and report, cryptocurrencies and cryptoassets to internal and external stakeholders. Intangible assets, whether classified as limited life of indefinite life assets are clearly an option for cryptocurrencies as these items are, in fact, intangible in nature. Treating cryptocurrencies as currencies might appear to be logical at first glance, but also would have to deal with the volatility embedded in these different currencies, as well as the reality that many organizations do not use these items in this manner. An additional option would be to report and classify cryptocurrencies as other equity securities (available for sale, trading, or held to maturity). Such treatment would align with tax treatment and reporting, but may increase volatility within financial statements in excess of the associated benefits with selection this methodology.

Based on the underlying analysis for the accounting treatment for cryptoassets, it appears that there is no one fit all solution. Cryptoassets, as discussed in this paper mostly mimic intangibles as these assets clearly meet the definition of an asset and do not have physical attributes. However, the main obstacle with their recognition deals with their origination. For cryptoassets purchased from the outside, we could apply the rules associated with externally purchased intangible assets with unidentified useful life and therefore subject them to period impairment. This comes with its own obstacles as we would need to periodically assess the fair value of these assets over time. However, such impediments would be warranted as the alternative is not reporting these assets all together. The most significant obstacles accountants have to deal with is internally created cryptoassets. If we are to use rules associated with internally generated intangible assets, we have to expense all of the costs as we incur them. This would create opportunities for management to manipulating earnings over time. An alternative proposition would be to capitalize these costs over time and subject them to periodic impairment similar to the external intangibles. This would be considered a ground breaking approach and it comes with its own obstacles. The most significant one of which is that the cost to internally acquire the cryptoassets would not reflect the cost to purchase it from a third party. Further analysis would be warranted to determine if such an approach has its own merits. 
Regardless of what treatment(s) are initially selected by an organization, an underlying reality is that the proposed guidelines and treatments will inevitably evolve and change over time. This is what makes this area of research and analysis applicable and of interest for both practitioner and academic professionals and publications. Analyzing, comparing, and debating the merits of alternative treatments appear to be items that will continuously influence and impact the accounting profession moving into the future. Experimentation and future research in this area are encouraged, specifically building out comparative analyses of how financial results might differ depending on the treatment selected. Additionally, engagement and collaboration with professional and industry associations should form a cornerstone of future research analysis to ensure an objective assemblage of guidelines. Cryptocurrencies, cryptoassets, and the reporting uncertainty associated with these items are creating both challenges and opportunities for accounting professionals, including an opportunity to play a leadership role in this rapidly developing area.

\section{REFERENCES}

AICPA (2016), Comments on Notice 2014-21 dated June 10, 2016, https://www.aicpa.org/Advocacy/Tax/DownloadableDocuments/AICPA-Commen t-Letter-on-Notice-2014-21-Virtual-Currency-6-10-16.pdf.

ADAMS, E. W.; SUMUTKA, A. R. (2018): “Documenting Virtual Currency Transactions.” Journal of Accountancy, vol. 225, n. 1: 8-10. https://www.journalo faccountancy.com/issues/2018/jan/documenting-virtual-currencytransactions.html

BJERG, O. (2016): “How is Bitcoin Money?”, Theory, Culture \& Society, vol. 33, n. 1: 53-72. https://doi.org/10.1177/0263276415619015

CARLOZO, L. (2017a): “What is Blockchain?”, Journal of Accountancy, vol. 224, n. 1: 1-2. https://www.journalofaccountancy.com/issues/2017/jul/what-isblockchain.html

CARLOZO, L. (2017b). "Understanding Blockchain”, Journal of Accountancy, vol. 224, n. 2: 1. https://www.journalofaccountancy.com/issues/2017/jul/what-isblockchain.html 
DAI, J.; VASARHELYI, M. A. (2017): “Toward Blockchain-Based Accounting And Assurance”, Journal of Information Systems, vol. 31, n. 3: 5-21. DOI:10.2308/isys-51804

DE FILIPPI, P. (2014): "Bitcoin: A Regulatory Nightmare to a Libertarian Dream.” Internet Policy Review, vol. 3, n.2,:1-12. DOI: 10.14763/2014.2.286

FASB Statement 6 (1985): Statement of Financial Accounting Concepts No. 6, Elements of Financial Statements, Definition of an Asset, pp.25-34. https://www. fasb.org/jsp/FASB/Document_C/DocumentPage?cid=1218220132802\&accepted Disclaimer=true

FASB Statement 142 (2001): Financial Accounting Standards Board, Statement No. 142, Goodwill and other Intangible Assets. https://www.fasb.org/jsp/FASB/ Document_C/DocumentPage?cid=1218220124961\&acceptedDisclaimer=true

HERIAN, R. (2018): "Regulating Disruption: Blockchain, GDPR, and Questions of Data Sovereignty”, Journal of Internet Law, vol. 22, n. 2: 1-16. http://oro.open .ac.uk/id/eprint/56264

IRS (2014) Notice 2014-21, 2014-16 I.R.B. 938, https://www.irs.gov/pub/irsirbs/irb14-16.pdf.

I.R.C. (1986a) Chapter 26 of the U.S. Code §317(a) “Other definitions” http://us code.house.gov/statviewer.htm?volume=68A\&page $=99$

I.R.C. (1986b) Chapter 26 of the U.S. Code §1031(a) "Exchange Of Real Property Held For Productive Use Or Investment” http://uscode.house.gov/statviewer.htm? volume $=68 \mathrm{~A} \&$ page $=302$

I.R.C. (1986c) Chapter 26 of the U.S. Code §7602(a) "Examination Of Books And Witnesses” http://uscode.house.gov/statviewer.htm?volume=112\&page=751

IRS (2015). IRS Agent David Utzke Affidavit. https://www.courtlistener.com /recap/gov.uscourts.cand.308850.1.1.pdf.

JACKSON, O. (2018): "IRS Intensifies Enforcement Efforts Against Cryptocurrencies.” International Financial Law Review. https://www.iflr.com /Article/3829517/IRS-intensifies-enforcement-efforts-against-Cryptocurrencies .ht ml?ArticleId $=3829517$ 
KAUFMANN, L.; SCHNEIDER, Y. (2004): "Intangibles: A Synthesis of Current Research”, Journal of Intellectual Capital, vol. 5, n. 3: 366-388. https://doi.org/10.1108/14691930410550354

LAI, K. (2018): “Blockchain As AML tool: A Work In Progress”, International Financial Law Review. https:/www.iflr.com/Article/3804315/Blockchain-asAML-tool-a-work-in-progress.html?ArticleId=3804315

LUTHER, W. J. (2016): “Cryptocurrencies, Network Effects, and Switching Costs,” Contemporary Economic Policy, vol. 34, n. 3: 553-571. https://doi.org/10.1111/coep.12151

LUTHER, W. J. (2015): "Bitcoin And The Future Of Digital Payments." Independent Review, vol. 20, n. 3: 397-404. https://doi.org/10.2139/ssrn.2631314

LY, M. K. M. (2013): “Coining Bitcoin's Legal-Bits: Examining Framework For Bitcoin And Virtual Currencies.” Harv. JL \& Tech.

PAGLIERY, J. (2014): “Bitcoin: And The Future Of Money.” Triumph Books, Chicago, IL: 80-90.

REYNOLD, P.; IRWIN, A. S. (2017): “Tracking Digital Footprints: Anonymity Within The Bitcoin System”, Journal of Money Laundering Control, vol. 20, no. 2: 172-189. https://doi.org/10.1108/jmlc-07-2016-0027

SONTAKKE, K. A.; GHAISAS, A. (2017): “Cryptocurrencies: A Developing Asset Class”, International Journal of Business Insights \& Transformation, vol. 10, n. 2: 10-17. DOI:10.1080/1540496X.2016.1193002

SMART, E. (2015): “Top 10 Countries In Which Bitcoin Is Banned.” https://www.ccn.com/top-10-countries-bitcoin-banned

US. Treasury (2018) Treas. Reg. §1.1001-1(a). “Computation Of Gain Or Loss. https://www.govinfo.gov/content/pkg/CFR-2018-title26-vol13/xml/CFR-2018title26-vol13-sec1-1001-1.xml

UNITED STATES V. COINBASE, Inc., (2017) Case No. 17-cv-01431 (ND CA 2017)

YERMARCK, D. (2015): “Is Bitcoin A Real Currency? An Economic Appraisal”, In Handbook Of Digital Currency, pp. 31-43. https://doi.org/10.1016/b978-0-12802117-0.00002-3 